\title{
ROA CLUJ: REKO TYPE SUSTAINABLE MARKETING NETWORK IN ROMANIA
}

\author{
Kinga Xénia HAVADI-NAGY \\ Babeş-Bolyai University, Faculty of Geography, Cluj-Napoca, ROMANIA \\ kinga.havadi@ubbcluj.ro, (D) https://orcid.org/0000-0002-9182-3824 \\ DOI: http://doi.org/10.23740/TID220211
}

\section{ABSTRACT}

The trend of sustainable consumption induces a change in the marketing strategies, applying a marketing type that promotes the culture of quality, and employs the principles of eco-rationality in choosing the tools of interaction with the consumers. The originally Finnish REKO (abbreviation of the Swedish "Rejäl Konsumtion", meaning "Fair Consumption") model of alternative food network (AFN) is a perfect example of implementing the principles of sustainable marketing. This survey focuses on ROA (Roade Online din Ardeal; Fruits/Harvest from Transylvania online), a REKO type direct marketing network, based in Cluj-Napoca, Romania. The aim of the study is to assess the chances and challenges of this type of AFN in the Romanian context. For this, we analyse the opportunities and impediments of development, and the cost and benefits of the AFN for the involved producers. The objective of the survey is to reveal the potential contribution of AFNs to sustainable production, marketing, and distribution of local products. The applied qualitative research is based on (1) an interview with a coordinator of the investigated initiative, (2) a survey among the involved producers, (3) participant observation as consumer, (4) informal discussions with the AFN stakeholders, and (5) secondary data analysis. As conclusions, we can state that Romania holds significant resources for the implementation of AFNs due to numerous favourable circumstances, such as the rising demand for qualitative local and regional products, and the willingness of consumers and producers to get involved in direct marketing networks. However, grassroot initiatives of direct marketing face administrative and legal challenges. The lack of real support of public policies, the weakly developed idea of self-government, and not firmly established in practice, confine the short food supply chains to a niche phenomenon.

Keywords: Farm to Fork, Romania, short food supply chain, smallholders

Cite this article as: Havadi-Nagy, K.X. (2021). ROA Cluj: REKOType Sustainable Marketing Network in Romania. Territorial Identity and Development, 6(2), 5-24. DOl: http://doi. org/10.23740/TID220211

\section{INTRODUCTION}

Sustainable consumption encompasses avoiding excessive shopping, restricting all kind of wastefulness, as well as manifesting predilection for products and services which comply with specific ethical, social, and environmental criteria (Szymoniuk \& Valtari, 2018). Sustainable consumption is a decisive element of the overall economic and social sustainable development, both on a global and local level (Szymoniuk \& Valtari, 2018).

Food provision, in the shape of local food consumption, is an everyday practice of sustainable and ethical consumption (Kumar et al., 2021). Besides the physical distance, main elements in defining local food are the limited quantities characteristic for smallholders, the environmentally 
friendly production methods, the benefits for producers and consumers, and the distribution systems through which these goods reach the consumers (Kumar et al., 2021).

Food marketing activities play a critical role in bringing together agricultural stakeholders, enhance food security, simulate food safety and the consumer. Every generation elaborates creative ways to integrate production, marketing, distribution, and technology to achieve the optimal manufacturing and marketing of food resources (Sadiku, Ashaolu \& Musa, 2019). Thus, the trend of sustainable consumption induces a change in the marketing strategies, applying a type of marketing that promotes the culture of quality, and employs the principles of ecorationality in choosing the tools of interaction with the consumers (Szymoniuk \& Valtari, 2018). "Marketing 4.0" (Martínez-Ruiz et al., 2021) reflects the impact of the current communication technology in the marketing area. Contemporary businesses, which assure a major role for the consumers in the stages of their on- and offline path to purchase, can improve their profits and communication effectiveness and can be competitive on the market (Szymoniuk \& Valtari, 2018). Implementing new generation solutions, both technical and organisational, joining quality expectations, resource efficiency and reducing negative externalities (Szymoniuk \& Valtari, 2018) improve the chances on the market.

The REKO model of alternative food network (AFN) is a suitable example of applying the principles of sustainable marketing. Founded in Finland in 2013 (Ehrnström-Fuentes \& Leipämaa-Leskinen, 2019), it is a face-to-face short food supply chain, where a customer buys food products in immediate personal contact with the manufacturer, a direct relation which assures authenticity and trust (Renting \& Marsden \& Banks, 2003) in the commercial interaction. The name is an abbreviation of the Swedish "Rejäl Konsumtion", meaning "Fair Consumption" (Ehrnström-Fuentes \& Leipämaa-Leskinen, 2019). The REKO local food groups connect producers and consumers and facilitate consumers' access to locally produced food at regular intervals, without the intervention of any middleman. The REKO basic functional units are local Facebook groups. Consumers order food from producers through these closed Facebookgroups (Interreg Europe, 2017). Producers deliver the products to agreed exchange places, usually on a weekly basis. The units are built by administrators, producers, and consumers. These administrators can be both customers and producers. They create and manage the group (Interreg Europe, 2017). The administrators were given a key role in the local groups, as they were responsible for setting up a Facebook group, deciding on a place and time for deliveries, and accepting or rejecting the group's producers and consumers. Membership is open to everyone by application (Ehrnström-Fuentes \& Leipämaa-Leskinen, 2019), and the customers are not constrained by minimal orders or purchases.

Given the Finnish origin and the longest existence in this country, several Finnish researchers, but not only, addressed the phenomena and analysed it under various foci, whereat the consumer is predominantly under scrutiny. Researchers are intrigued by the demographic profile of the REKO local food consumers (Engeseth, 2020; Murphy, 2020), or they investigate the consumer behaviour and purchase intentions (Murphy, 2020; Kumar et al., 2021), and even the consumer drop out (Lam, 2020). A further consumer-centred survey analyses the complex social processes among the actors of a food network, and how they deal with conflict situations (Ehrnström-Fuentes \& Leipämaa-Leskinen, 2019). With the emphasis on the local food consumption in the frame of REKO as a form of mundane consumer resistance, LeipämaaLeskinen (2021) highlights the socio-ecological activism feature of these initiatives. Further on Szymoniuk and Valtari (2018) argue for the REKO food network as a model for sustainable marketing channels, whereat most of the authors consider the environmental, economic and social sustainability features of this alternative food network opposite the conventional food 
network (e.g. Engeseth, 2020; Kumar et al., 2021; Leipämaa-Leskinen, 2021). REKO producers' perceptions and concrete experiences of sustainability are voiced in the assessment of Ehrnström-Fuentes, Jauho and Jallinoja (2019).

Although the use of social media to market foods and beverages has exploded, online food direct marketing systems have remained largely underexplored in the local food research of Romania, even though as a ROA producer explains it, "the online domain is our outlet market, the place where we present our producers, products, respectively offers" (Lică, 2021; our translation). In this survey, we focus on the producer members of the ROA (Roade Online din Ardeal; Fruits/Harvest from Transylvania online) alternative food network operating according to the principles of REKO groups. This "neotraditional" (Santini \& Gomez y Paloma, 2013) short food supply chain is a complex off-farm collaborative network established in an urban area, and with emphasis on social, ethical, and environmental principles. The study aims to assess the chances and challenges of success of this short food supply chain in the Romanian context. For this, we analyse the opportunities and impediments of development, the driving forces behind it and the cost and benefits of the AFN for the involved producers. Further on, we draft the demographic and professional profile of the producers participating in this model of direct selling.

\section{METHODOLOGY}

As mentioned above, the REKO networks consist of the following stakeholders: producers, consumers and administrators, role which can be performed by both above. In our study, we only partially tackle the consumers, but focus mainly on the producer side of the network.

As main objectives of this survey, we can name the following:

1. Verifying the features of the ROA network as a sustainable marketing channel;

2. Drafting a profile of the network's producers;

3. Identifying the motivations of the participating producers, determining advantages and disadvantages of the membership;

4. Investigating the contextual elements which could endorse or hinder the development of these type of food networks in Romania.

To achieve our goal, we carried out a qualitative research based on interview, survey, participant observation and secondary data analysis (Table 1). We also applied the case study research strategy, considering the REKO type short food supply chain established in Cluj-Napoca, Romania.

At first, we assessed secondary data represented by relevant media texts (blog posts and newspaper articles) using Google to search for key words referring to ROA. For this scheme, we identified a short video broadcasted by a regional TV, but also available on YouTube and included on the Facebook (FB) platform of the group.

The group's Facebook account was a main source of information for ROA, Facebook being most suitable, since this is the platform on which REKO groups operate and due to FB's a priori social feature, which advocates for content share. These materials (1) not only delivered information about each producer and their products, (2) facilitated data about the network and the list of rules and principles according to which they operate, (3) but also enabled us to have a glimpse into the dynamics of the group in the online sphere. 
After a first assessment of the secondary data, we drafted a guide and conducted a semistructured interview with one of the co-founders of the investigated initiative, who also functions as administrator of the group. The interview guide consisted of seven sections: (1) introductory questions regarding the background of the interviewee; (2) questions about the way the network functions; (3) a further section addressed the producers and the products; (4) the following deliberated upon the marketing and distribution strategies; (5) costs and benefits for the producers were also addressed; (6) as well as challenges of the alternative food supply chain; (7) and finally, future projects as a community. The interview was conducted in June 2021 via Zoom platform, lasted about 50 minutes, and was recorded with the consent of the interviewee.

Following the interview, we finalised the questionnaire for the survey we applied among the network's producers, where 16, mostly closed questions addressed similar topics as the interview and delivered relevant information about (1) the personal and professional profile of the participating smallholders (e.g. age, training in the field of food production and/or processing); (2) the product range they offer (e.g. product type and process of production); (3) details regarding their enterprise (e.g. legal form, location, founding year, used marketing channels); (4) as well as their history with the ROA short food supply chain, and costs and benefits of being member of the analysed alternative food network. In June 2021, our interview partner distributed the online questionnaire among the network producers, and we gathered 16 responses from the 18 core producers of ROA.

The author was an occasional consumer of the surveyed network also before she conducted the research, the position of participant-observer allowing to gain deeper insight into the AFN on various levels, but mainly on the interactions at the weekly meeting points. These meetings were also opportunities for informal discussions with AFN stakeholders.

Table 1: Research data used in the analysis

\begin{tabular}{|l|l|l|}
\hline Type of data, source & Research data \\
\hline Interview with scheme initiator & 1 interview with a co-founder of ROA Cluj & Non-participatory \\
\hline Survey among the producers & 16 responses/18 producers (June 2021) & Non-participatory \\
\hline Media presence & $\begin{array}{l}2 \text { online articles, March and May 2021; } \\
1 \text { video }\end{array}$ & Non-participatory \\
\hline Social network & Facebook group & Participatory \\
\hline Participant observation & Author as consumer & Participatory \\
\hline
\end{tabular}

Source: The author

On the collected information we employed a qualitative and quantitative content analysis, also considering the main marketing characteristics: packaging, price, advertisement, distribution, regulations, and ethics (Sadiku, Ashaolu \& Musa, 2019). 


\section{RESULTS AND DISCUSSION}

The "Farm to Fork Strategy" of the European Union (EU), as part of the European Green Deal, aims to make food systems fair, healthy and environmentally-friendly (European Union, 2020). Guiding food systems into a sustainable direction facilitates new opportunities for operators in the food value chain. The aim is to ensure benefits for all stakeholders, with special focus on improving the income of primary producers. This should be accomplished due to new technologies and scientific discoveries, combined with increasing public awareness and demand for sustainable food (European Union, 2020). Supporting short food supply chains is an instrument to enhance the economic benefits of the primary producers, to contribute to healthy nutrition of the population, and these under environment-friendly circumstances.

REKO groups are methods to market local products of smallholders that have no access to the market since they are manufactured on small scale or in a region which has no suitable markets for it (Interreg Europe, 2017). Despite some assessed weaknesses of the system, the European Regional Development Fund promotes the REKO-type short food supply chain as a good practice (Interreg Europe, 2017). This model of AFN complies with the goal of the "Farm to Fork Strategy" of the EU of supporting the primary elements of the food value chain, namely the producers, in gaining more benefits, but at the same time producing and distributing healthy local food in a sustainable way.

The strategic choice to use Facebook as the communication and sales platform has facilitated the exponential growth and spread of the idea in Finland, where in 2019 were functioning over 200 local groups, with estimated 280,000 members (Ehrnström-Fuentes \& Leipämaa-Leskinen, 2019). Lately the REKO scheme started to expand abroad. In Sweden, there were over 120 local REKO groups in 2019 (Leipämaa-Leskinen, 2021). Besides other Nordic countries, the REKO network spread also in Canada, Ireland, or Italy (Leipämaa-Leskinen, 2021). Considering this process, REKO is exemplary on how self-governed grassroot initiatives can grow through replication and shape food provisioning practices beyond just the locality of their original emergence (Ehrnström-Fuentes \& Leipämaa-Leskinen, 2019). Almost anybody can create a REKO group, but necessarily following four guiding principles: (1) goods must be local; (2) retail selling is not allowed; (3) products should be ethically or organically produced; (4) transparency must be secured, whereat the producer communicate details on production and processing (Ehrnström-Fuentes \& Leipämaa-Leskinen, 2019).

However, the implementation of the REKO system depends on several preconditions: (1) from a technological point of view there is a widespread internet access, (2) in the social aspects are prevalent high-level social network skills, (3) the producers are confined to honesty and transparency in conducting their local business and applying the concept of sustainable marketing, and (4) from the consumers is expected a high level of environmental consciousness, brand loyalty and a certain level of local patriotism (Szymoniuk \& Valtari, 2018). Complementary to these premises, the Romanian example provided us a further requirement, not a necessary precondition for the establishment of the group, but significant in ensuring the long-lasting successful existence, namely a legal framework and political willingness from the responsible authorities.

\section{REKO in Romania}

The first REKO type food direct selling model in Romania was ROMO Brașov, established in the autumn of 2020. It was a grassroot movement started by an egg farm owner who wanted to 
create a market for the family business, and it turned into a modern direct marketing opportunity for a large group of smallholders (Bunilă, 2021). The network started with one producer and 500 members of the Facebook group. In the following three months, both the number of producers and consumers registered an exponential growth, finishing the year 2020 with 40 local smallholders and over 11,000 Facebook group members. In January 2021, ROMO Cluj started its activity, showing similar growth tendencies. The objective of the initiators was to offer various support to the small-scale producers, and to bring together local producers and the consumers, with the broader vision:

"to contribute to food security in our country and the generation of well-being by activating resources locally. In order to fulfil this mission and vision, we have 3 strategies aimed at solving 3 major problems faced by small producers in our country: sales / distribution, marketing and various authorizations, and tax and legal advice" (Coșman, 2021; our translation).

The initiative helped smallholders to survive the COVID-caused restrictions, it helped others to grow and some to start an agricultural or food processing economic activity, it induced partnerships among the producers and created a community among all the members (Facebook ROMO, 2021b). Despite the complex goal of contributing to a sustainable food production, distribution and consumption, after eight months, end of May 2021, ROMO temporarily ceased its activity because of the lacking legislative frame for the innovative direct marketing scheme and a complaint from a grocery shop not welcoming the competition (Facebook ROMO, 2021b). For the time being, July 2021, ROMO did not resume its activity yet.

\section{ROA network}

To resolve the legal status of the REKO type direct marketing channel is also a challenge for the short food supply chain of our interest, ROA Cluj. However, our interview partner reports of courteous officials, and following consultancy with authorities and legal advisors, the ROA coordinators found the most favourable solution to formalise their activity and are in the process to establish as an association.

ROA is based in Cluj-Napoca, the second largest city in Romania, a vibrant university city and economic centre. This direct selling scheme developed as a reaction to a crisis, namely restrictions and social distance regulations triggered by the COVID-19 pandemic. In their endeavour to establish ROA, the five co-founders were originally guided by pragmatic reasons. They were already working with homedelivery, but the restrictions imposed by the pandemic from March 2020 on complicated their logistics. So, the main reason was to make deliveries more efficient, both for the producers, and for the consumers, to improve logistic issues, time management and to have time for their main occupation, meaning production.

The initiative aims to offer marketing opportunities for the producer members, to support local and regional smallholders. Therefore, there are no membership fees neither for the producers, nor the consumers. Another reason is to maintain the price at a reasonable level, accessible for the consumer and fair for the producer.

The first meeting took place on the $1^{\text {st }}$ of December 2020, but it was preceded by months of research, plans and deliberation about the most convenient way of organising the communication, ordering, purchasing and delivery process. The Google research for sustainable marketing solutions ended in the implementation of the REKO direct selling scheme based on advanced order. They even consulted with the initiator of the originally Finish model.

The REKO retail and distribution model adopted by ROA offers consumers a way of ordering 
products directly from the producer, without any intermediaries. The network operates, as any other REKO group, via Facebook as closed group in which orders and deliveries are communicated and agreed on. The FB closed group "ROA Cluj-vânzare directă" (ROA Cluj direct marketing) servesas the offer-order platform of the ROA stakeholders, whereas "ROA know and rate us" is an open account and serves for reviews and further announcements. The producers who wish to attend a certain delivery publish their intention and details about the offered goods (information about quantity, price, and the preferred payment method) on Facebook. The consumers order by specifying the wished products and quantities, as well as the pick-up site in the form of comments below the post of each producer.

The pick-up of the products ordered in advance takes place on a weekly basis, with two trade meetings each Tuesday and Thursday in the afternoon, after working hours and usually last for 60 minutes. The concentration of the deliveries on two afternoons allows producers and farmers to focus on the rest of the week on the production or other marketing possibilities.

The consumers come and pick up all products they have ordered at the same time from different producers. The four meeting points located in three different neighbourhoods of Cluj-Napoca and one in a suburban area, were established to be convenient for the consumers, taking into account the spatial concentration of the network's clients. The meetings take place in a public space, mainly in parking lots, as both the producers and consumer come mainly by cars, and on the other hand larger space was required also to maintain distance requirements according to the Covid-restrictions. Our interview partner recounted having positive experience with authorities and administrators of the meeting point sites.

Five producers attended the first meeting of ROA, after which the network grew steadily: between December 2020 and A pril 2021, two-three new producers joined the network monthly. The network coordinators recruit mostly new producers by presenting them their initiative. ROA coordinators and producers are responsible for about $50 \%$ of the new members. Other found out about ROA from family and friends (25\%) or from social networks (e.g. FB and Instagram) (18.75\%). Face-to-face and digital Word-Of-Mouth (WOM) is the main channel of information about the initiative (Figure 1). As we can see, producer members act and advocate for the network. To join, besides the quality food they provide, the producers should have similar values, be willing to interact with consumers, to get involved, to be part of a community, since, as expressed by one of the producers: "We resolve to create a network of direct marketing and conscious consumption for locally produced food" (ROA producer in Lică, 2021; our translation).

The five co-founders are also the administrators of the FB group and the coordinators of the activities, but all the decisions regarding the group are discussed and agreed upon together (Ziarul Clujean, 2021).

The face-to-face meeting with the consumers is an opportunity to respond to questions, maintain direct contact with the consumers, feel the pulse of the community, but also take advantage of the opportunity of awareness raising about the beneficial features of some rather unconventional products, such as donkey milk (ROA producer in Lică, 2021). Even though the initiative is very new, about seven months, it achieved a certain popularity and publicity, people address to the group regarding questions on fresh and healthy food, and there is an interest to supply events with their goods.

Furthermore, ROA is present in the local community as one collective. Our interviewee recounted for instance about a donation campaign on the $1^{\text {st }}$ of June 2021, the International Children's Day, where the producers contributed with products and consumers donated objects for children. The donation was then delivered to a charity organisation. 


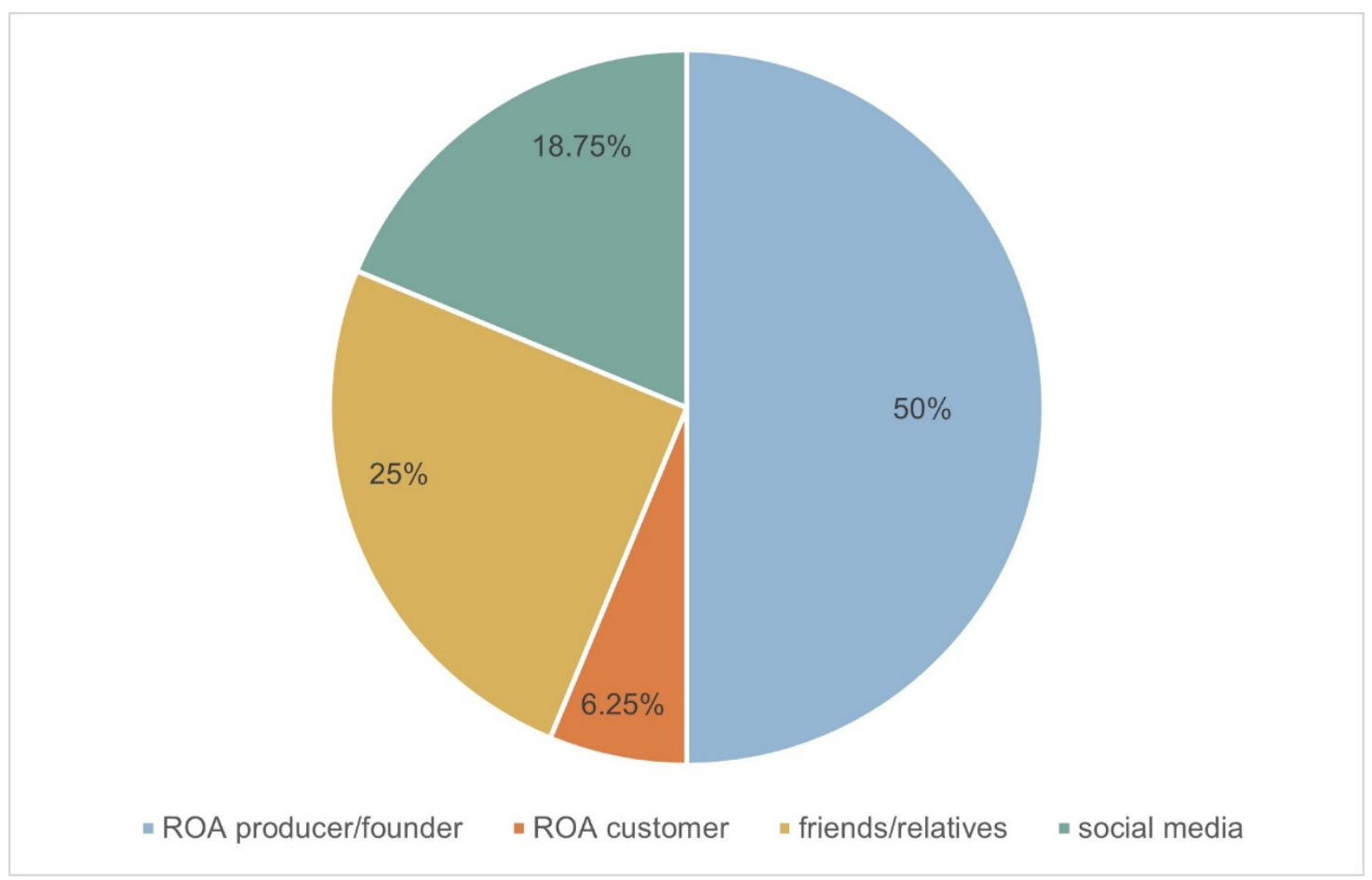

Figure 1: Recruiting new members for the ROA network

Source: The author

\section{ROA producers}

Currently the ROA network has a core of 18 members, who are regularly, on a weekly basis, present at the meetings. These are complemented by producers who offer their products and attend the meetings more rarely or occasionally, either because of the seasonal character of their products (mainly fresh seasonal fruits), or offer non-food products (handmade soaps, products made of lavender) or are not from the proximity (Facebook ROA Cluj, 2021a). Comparing to the more mature network in Finland, where in 2019 a number of 200 REKO groups gathered 4,500 producers (Ehrnström-Fuentes, Jauho \& Jallinoja, 2019), with only one active REKO group in Romania, we obviously notice a modest base of producers.

From the 16 respondents, 13 members of the ROA network (81\%) are from Cluj County (NUTS2), from different settlements in the proximity of Cluj-Napoca, the outlet market covered by ROA. Other three producers are from the neighbouring counties (two from Bistrița-Năsăud and one from Sălaj).

The ROA members are young entrepreneurs, with over $60 \%$ in the $27-35$ age group (Figure 2). Three producers (18.75\%) are even under 26 years of age, respectively other three are 36-55, the oldest age group present among the producers (Figure 3 ). This young age group might account for the openness and willingness of the producers to use these innovative alternative food networks to market their products. 


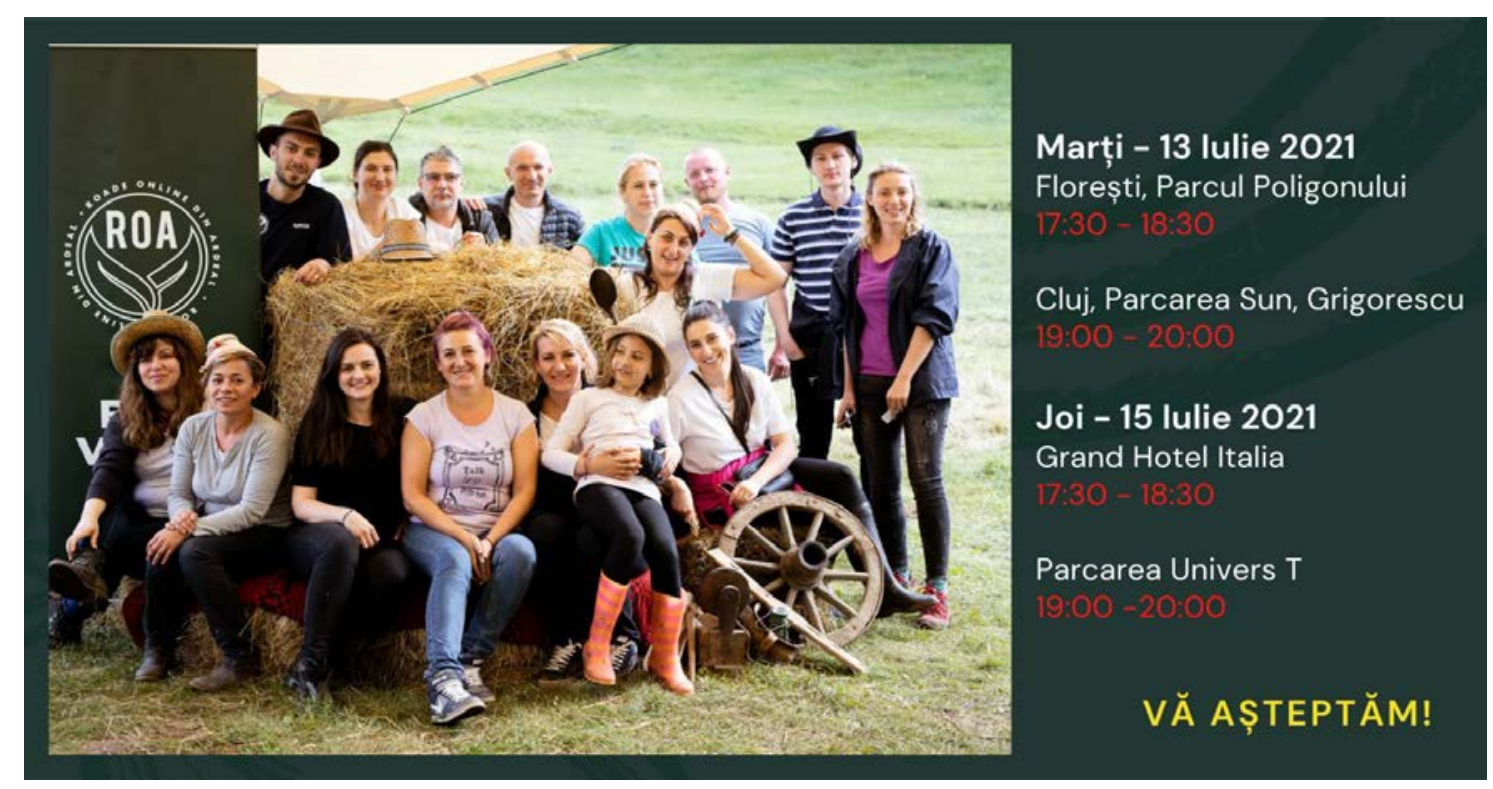

Figure 2: ROA producers

Source: Facebook ROA Cluj 2021a; Published with permission

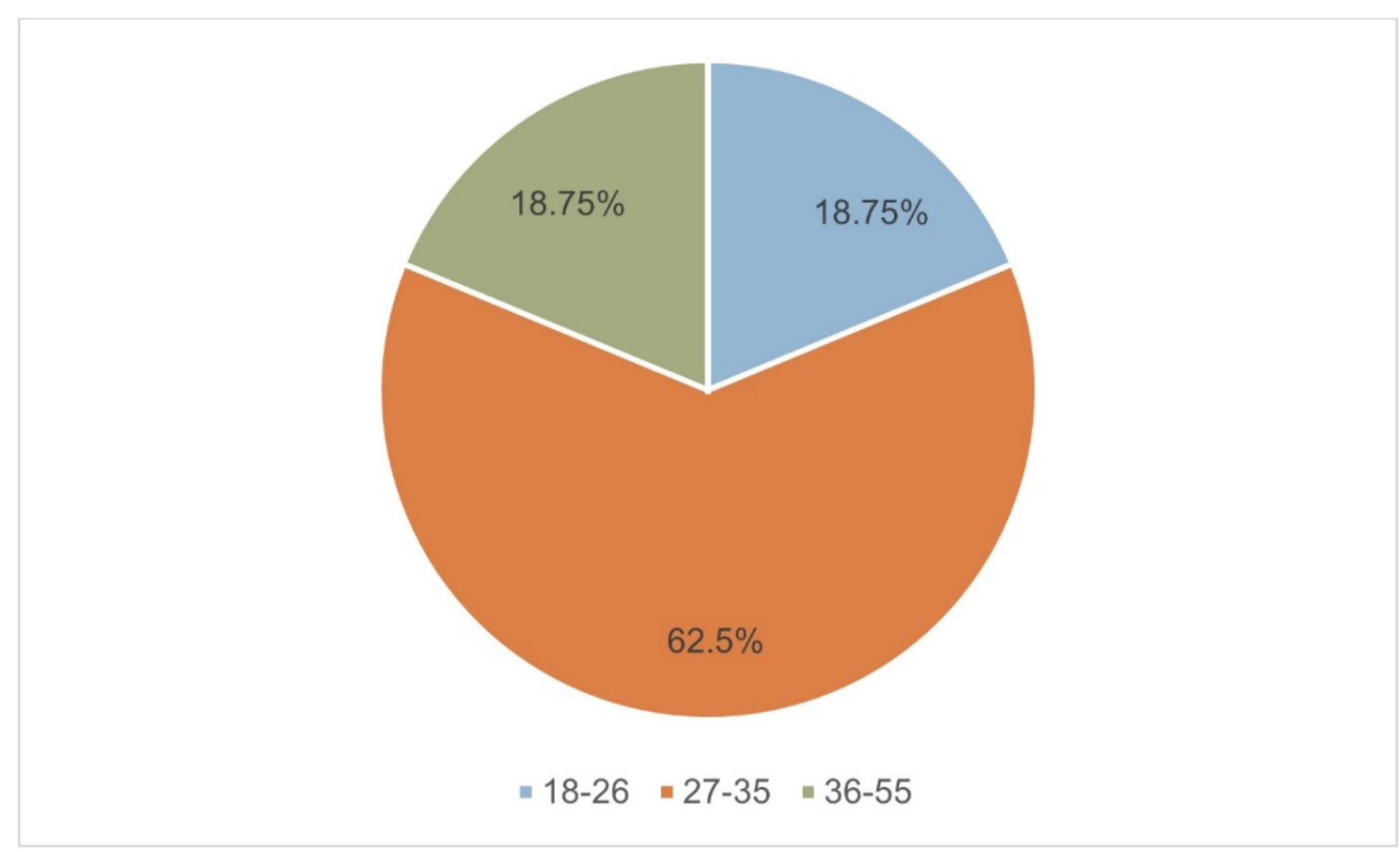

Figure 3: Age of the respondent producers

Source: The author

The predominant young age group explains also the fact that two thirds of the respondents are very fresh in the field, for 1-5 years, the other third is practicing food production for 6-10 years. 
Two thirds of the respondents conduct this activity as a full-time job, food production being their main income source.

All the ventures are very new, little over one third (37.5\%) started their activity in 2018, the oldest one was founded in 2013, and two began even only last year (Figure 4). All the members are registered companies and $75 \%$ of the surveyed producers are organised as a limited liability company.

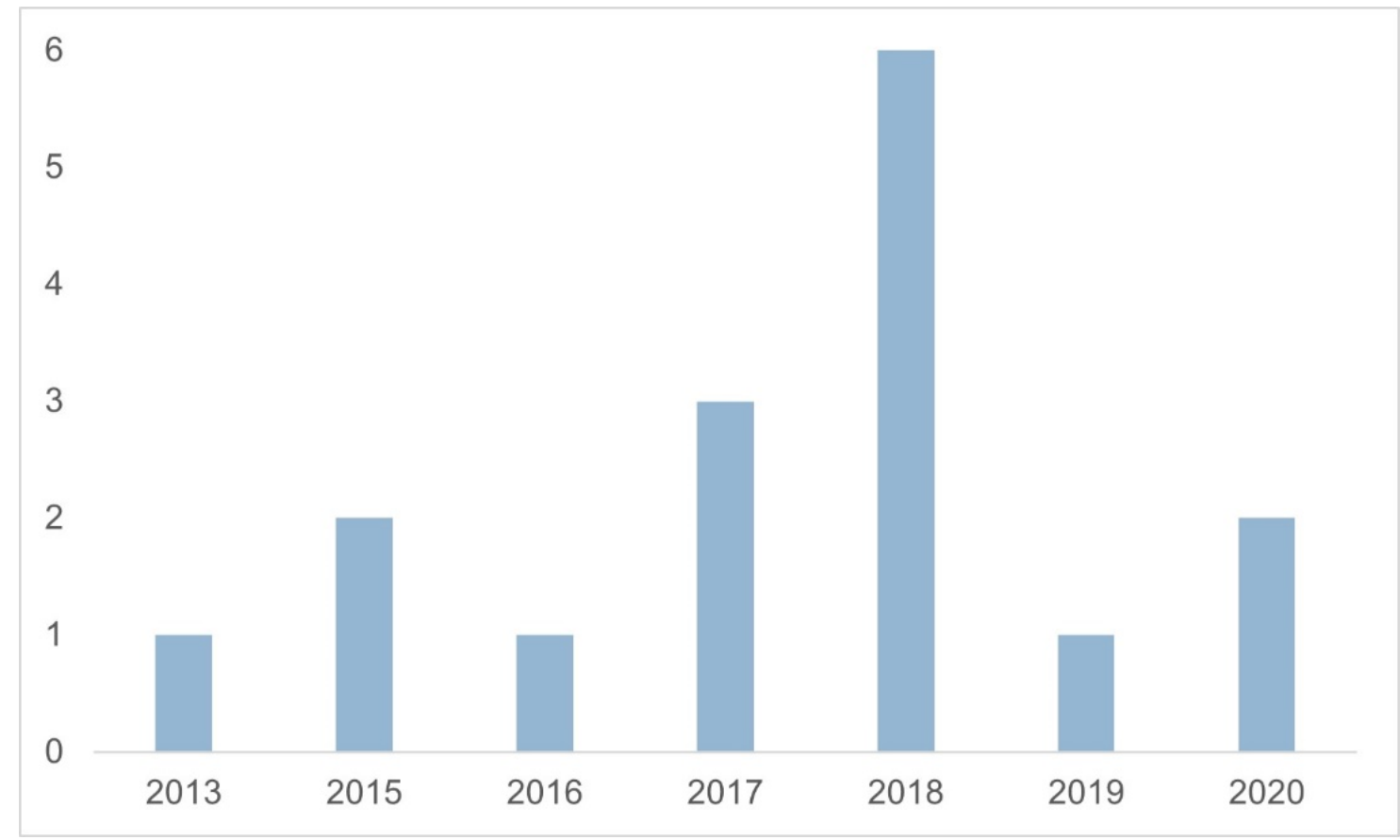

Figure 4: Founding year of the ventures

Source: The author

Regarding employees, we notice that the majority of the ventures, meaning over a half ( $56.3 \%)$, have no employees. The smallholders are mainly family businesses and cover the labour force with family members (Ziarul Clujean, 2021). The smallholder character of the ventures is reflected also by the fact that artisanal and mechanic production complement each other: the mushrooms are collected by people in the forests, the bread and the cheese are kneaded manually. The producers claim that they prepare the products like they would be for their own family, with care, patience, and pride (Facebook ROA Cluj, 2021a).

$56.25 \%$ do not have specialised training or education in their field of work, however they have practical experience. Some producers are currently following specialised studies, for instance one agriculturist from the vegetable farm is studying horticulture (Facebook ROA Cluj, 2021). At the same time, $43.75 \%$ of the respondent producers have completed a formal education. Some of the ROA members have evengraduated specialised studies and trainings, or gathered practice and experience abroad (United Kingdom, Italy, Switzerland) and invest this know-how in an own business back home (Ziarul Clujean, 2021). This shows that this kind of direct selling opportunities for foodstuff might make agriculture and food production a more appealing economic occupation, or even encourage local entrepreneurship of remigrated citizens, who can invest their abroad gathered know-how in their home region. 
ROA is only one of the mostly manifold marketing channels used by the majority of the producers, and also not the most important. $75 \%$ of the respondents market only $0-25 \%$ of their products through the network. Nevertheless, there are also $12.5 \%$ of the producers who sell half or even $75 \%$ of their goods through ROA (Figure 5).

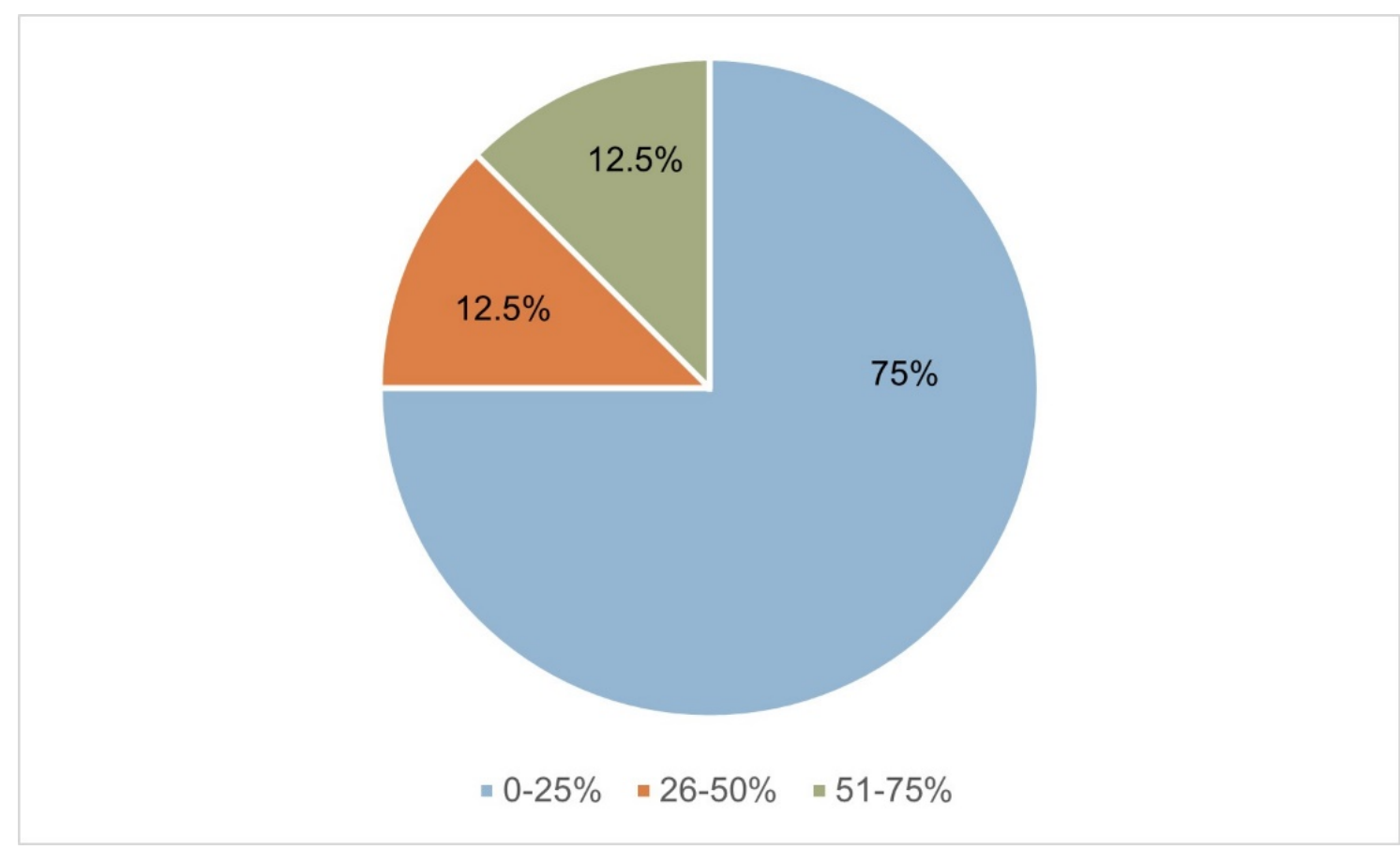

Figure 5: Percentage of the products marketed through ROA

However, other marketing channels used by the ROA members are short food supply chains as well: for instance, other AFNs similar to ROA (12.5\%), food hub schemes (25\%) or specialised retail shops who sell local/regional products (56.3\%). A quarter of the respondents have also their own shop and over a half (56.3\%) set up an own online shop to sell their goods. Other online shops and platforms are used by over one third of the respondents. A quarter sells also among friends, relatives and neighbours, but only one goes to the farmer's market. Four producers have also the HoReCa actors specialised in regional products as their customers and one participates at events (Table 2 and Figure 6).

Established about 6 months ago, the ROA network is a young initiative. Therefore, it is not surprising that for most of the involved producers it is not the most relevant marketing channel, and, to provide an economic and commercial viability, they use a multitude of sales channels. However, the main core of the producers had a relationship of cooperation built on trust, even before creating the ROA group. According to the data provided by the FB account of the group, there is a horizontal regional integration of supply and production among the smallholders, being partially the suppliers for the final products of the network members or using the fallout of others. For example, the chicken farm supplies with eggs the bakery from the network, and feeds its chickens with pumpkin seeds and the grist from the ventures producing cold-pressed oil; the products of the vegan and vegetarian food caterer contain various raw materials (e.g. vegetables, oil, cheese, spices and mushrooms) from the networks producers. 
Table 2: Other marketing channels, besides ROA, used by the producers

\begin{tabular}{|l|l|l|}
\hline Marketing channel & Absolute number & Percentage \\
\hline Only ROA & 0 & $0 \%$ \\
\hline Events & 1 & $6.3 \%$ \\
\hline Market & 1 & $6.3 \%$ \\
\hline Other food networks (similar to ROA) & 2 & $12.5 \%$ \\
\hline HoReCa & 4 & $25 \%$ \\
\hline Family, friends, neighbours & 4 & $25 \%$ \\
\hline Food hubs & 4 & $25 \%$ \\
\hline Own shop & 4 & $25 \%$ \\
\hline Other online shops & 6 & $37.5 \%$ \\
\hline Retail shops specialised in regional products & 9 & $56.3 \%$ \\
\hline Own online shop & 9 & $56.3 \%$ \\
\hline
\end{tabular}

Source: The author

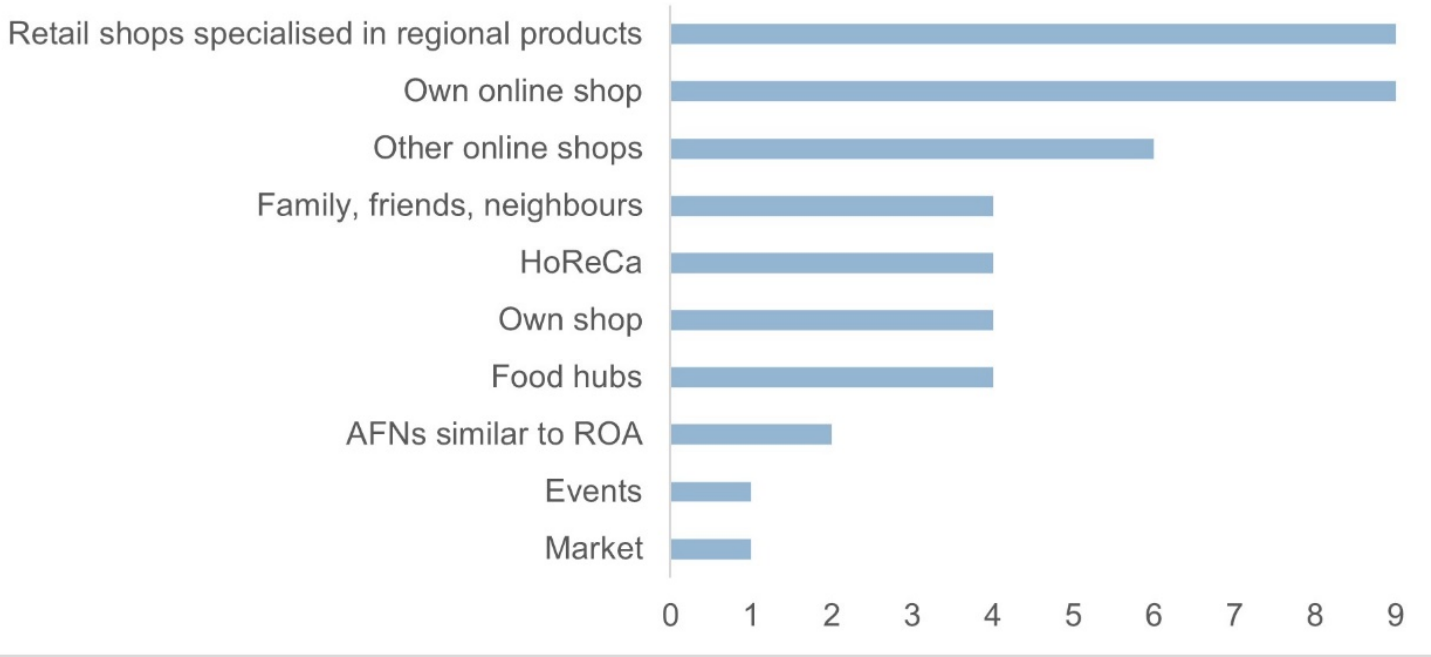

Figure 6: Marketing channels used by the ROA producers (absolute numbers)

$$
\text { Source: The author }
$$

\section{ROA products: organic, ethical, or conventional}

According to the interview partner, the aim of the network is to offer a variety of products, to cover all the basic foodstuffs which clients would like to buy at the same place. The initiators want to offer a wide range of products, but at the same time they do not want to create a competitive environment among the producers, so they avoid having multiple members offering the same goods. For now, the core of 18 producers covers the demand for the following product types: milk and dairy products, mainly cheese, dried and smoked fish and fish products, meat cold cuts, bread and pastry, eggs, fresh and processed fruits and vegetable (e.g. gems, juice, pesto, zacusca (spread on vegetable basis), dried fruits, spices), cold-pressed oil, pasta, sweets and wine (Facebook ROA, 2021a; Legat de Cluj LDC, 2021). Basic food stuff, mainly not processed, is marketed by all the REKO networks, whereas fresh fruits and vegetables, eggs, meat and dairy are the core of the offer (e.g. Engeseth, 2020; Lam, 2020; Murphy, 2020). In the 
case of ROA, besides basic food, the network provides innovative foodstuff, like donkey milk or micro plants, cheese specialities or liquid nitrogen ice cream.

Half of the respondents states that they produce organic but without being certified. One producer is certified for organic products, three producers $(18.75 \%)$ are presently in the process of certification and $25 \%$ of the respondents produce applying conventional methods (Figure 7 ). In this sense, the applied production methods respect the guiding principles of the REKO networks, namely ethically or organically produced goods (Ehrnström-Fuentes \& LeipämaaLeskinen, 2019).

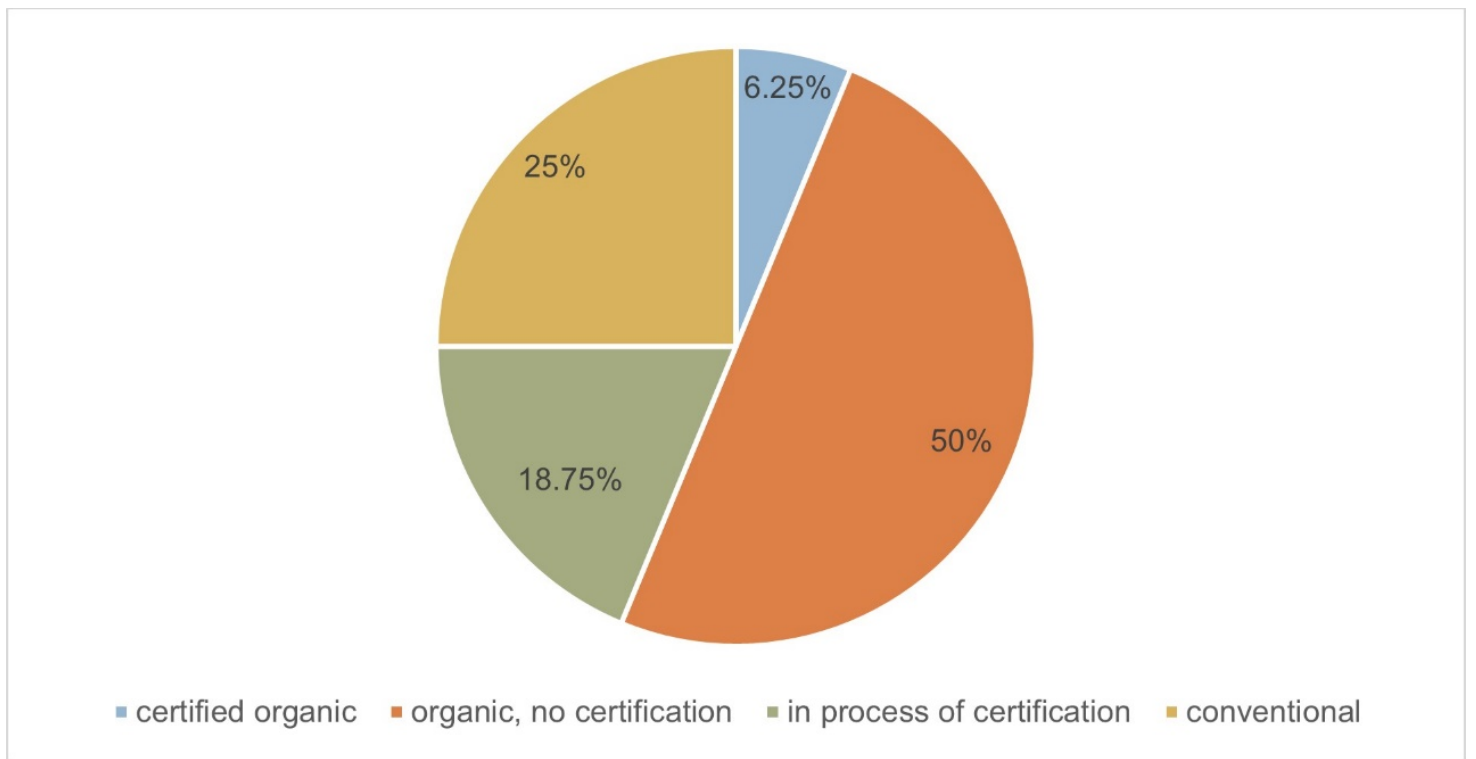

Figure 7: ROA products: organic, ethical, or conventional

Source: The author

In Romania, to become certified, the producers must undergo a long and heavily bureaucratic procedure and be subjected to random inspections and sampling. The process of transitioning from standard to certified agriculture is not affordable for everyone. Thus, organic certificates can have an exclusionary effect, both among the producers and the consumers, creating consumption inequalities (Delibas, 2021). Direct selling networks address this issue by reintroducing social relations into the food system, fostering one of care and reciprocity. It would be a false claim to affirm that alternative food networks function totally outside the market's logic, but certain aspects of these marketing strategies cannot be explained only with utilitarian terms. Basically, the trust built up through the direct relationship between consumer and producer is the base for the economic rent of the farmers and food processors (Delibas, 2021).

A main argument of the AFN is that it offers quality products, "clean" products, as the co-founder of ROA expresses the main feature of the foodstuff they provide. The term "clean food" is particularly used in place of organic or bio, which would only be possible based on certification. "Clean food" is not strictly defined, but according to the survey of Nistor (2015) among consumers of a Romanian AFN, basically means non-invasive agriculture practices and food production process, sustainably grown and produced, even if not certified. Besides the noninvasive production practices, a further aspect of environmental sustainability is the packaging: 
some of the ROA producers take back and reuse packaging (glass bottles and glasses, egg box), other strive to use little, less wasteful and more informative packaging. They also encourage the consumers to a sustainable way of managing packaging and food waste.

Certified products are appreciated, but also more costly, so the AFN try to cover the needs and purchasing capacity of the consumers, offering both, certified and non-certified products, for convenient prices.

\section{ROA consumers}

The inception of this short food supply scheme in Cluj-Napoca can be put in relation to several factors. Being one of Romania's largest cities, with a strong economic growth, that has made it a regional centre for industry and services in the last decades, Cluj-Napoca has attracted both capital and qualified workforce resulting in a growing middle-class population, which has both the resources and interest in quality food (Delibas, 2021). Even though the consumers are not our main concern, we asked the interviewed ROA coordinator about her insights regarding the consumers. She considers that the AFN is approached by conscious consumers, who care about the community and the environment, whereat the main group of consumers are financially wellsituated young families with children, who pay attention to fresh and healthy nutrition. This appreciation confirms the consumer attitude pointed out in other surveys on REKO networks, where freshness, nutritional value, and taste as driving forces to purchase local food, are completed by the aim of supporting local farmers and food producers (Kumar et al., 2021; Lam, 2020). Families with small children are also an important consumer group identified by Mikko Murphy in his study (2020) about the Finnish REKO groups, though older age groups are also well represented, and the income categories are varied.

The initial pool of ROA consumers was created by the clients' base brought in by each of the joining producer. This was steadily developed in time mainly through off- and online WOM, thus the experiences of others (family, friends, influential Internet users) have a significant impact on customers' purchasing decisions. ROA consumers' advocacy is related to the changes occurring in the attitude of contemporary consumers that perform informative-persuasive actions in the frame of marketing channels which fusion the online realm with the offline worlds. Thereby they are stakeholders of a market populated by new, hybrid actors, such as customers who are active in co-creating the offer and advocating for goods, brands, and services; social networks which provide traditional advertising and contribute to the transparency of a venture; cooperation platforms, places where the product is drafted in the process of interaction with the customers (Szymoniuk \& Valtari, 2018).

\section{ROA benefits and motives for participation}

Being part of the ROA network should be of mutual benefit for producers and consumers. Common for the REKO groups are the benefits identified by Sushant Kumar and peers (2021), namely that this marketing channel enables smallholders to sell their products in close locations reducing food waste, unnecessary storage, and transportation costs, and receive valuable feedback from consumers. The producers benefit from the fact that their products are ordered in advance and sold quickly. Drawn on their research on Finnish REKO groups, EhrnströmFuentes and Leipämaa-Leskinen (2019) identified the following motivations of producers: from an economic point of view, of importance are the access to new markets, the increase of profits and the possibility to set up new business. From a social perspective, the authors mention the 
education of consumers about local food as motivation to participate in the REKO network. As an environmental aspect, we can regard the idea of converting production methods to more small-scale methods.

The possibility of raising awareness about healthy nutrition and sustainable food production is mentioned also by the ROA producers, mainly in the context of regular direct contact with consumers. Among the ROA producers, there is also a general agreement regarding the access to a new market through this network, over $80 \%$ of the surveyed producers pointing it out as an advantage.

Observing the survey, we can also state that ROA offers an easy, uncomplicated membership. Being part of a community is of importance for all the respondents. Furthermore, the regular meetings with fellow producers, and the direct contact with consumers and their feedback are meaningfulfor the respondent ROA producers.

Our interviewee stresses the integration efforts the administrators conduct, striving to strengthen the group, "create a community where we know our customers, to build a relationship based on trust and mutual respect" (ROA co-founder in Ziarul Clujean, 2021; our translation). These ideas reflect the sense of the community provided by the network, and are not dreams of the future, but concrete plans and measures to be soon implemented. Namely community building actions, like brunches and tasting events for the ROA community shall take place monthly, the first being scheduled for July 2021.

The statement of the co-founder of the group shows commitment of the initiative both to the member producers and consumers, as well as to quality services and goods, as they aim "to grow and to become a quality brand, and this goal can be achieved by being committed to what we do, both in the case of our products and the group itself" (co-founder of ROA in Ziarul Clujean, 2021; ourtranslation).

For the consumers, ROA is a possibility to easily obtain locally produced foodstuff. Consumers do not have to make any binding agreements or follow strict timetables. As pointed out also by Szymoniuk \& Valtari (2018), the programme offers flexibility, as the consumers can order the products when they find it suitable, keeping in mind a certain deadline of the orders for the weekly meetings. Consumers have access and can order different products from various smallholders at the same place in a very simple way on FB, a familiar and free of charge online tool, whenever and wherever with a device connected to the internet. REKO enablesconsumers to personally meet the producers and a community of people with similar interest and values regarding the conscious consumption and locally production of healthy food. It facilitates to obtain more information about the raw materials and the production process, to directly support local farmers, and avoid intermediaries that increase the product price (Kumar et al., 2021). All this is possible without imposing a minimum order, transport costs from each producer, and they can choose each week what variety and quantity they want without being conditioned by a predefined box scheme.

The size of the group should guarantee enough orders from consumers per delivery to make the trip reasonable for a given producer. However, if every now and then some producers have few orders, they organise the delivery among the group members and the consumer is notified from which attending ROA producer can he pick up the ordered foodstuff. 


\section{ROA challenges and difficulties}

Besides benefits, some challenges and difficulties occur as well. The greatest challenge is caused by the fluctuation in the orders. This is a fact mentioned both by the interview partner and the surveyed producers. The co-founder of ROA explains it on one hand by the fact that the consumers are not bonded by fees, contractual agreements, or any obligations of minimum order, but on the other hand by the travel and holiday seasons, when customers are away or need less food. This is mainly the reason why the producers consider the ROA scheme only somewhat helpful in the planification of production and harvesting.

The FB group counts currently (16 June 2021) about 12,900 members. However, according to the order placements in the FB group, only a fraction of the group members is active, regular, or occasional consumers. Engaging consumers in REKO regularly and in the long run is also a challenge identified by Lam (2020) for the mature market for REKO in Finland. The study found that while REKO is an AFN in its conceptualization, it is embedded with the overall food provisioning system, and competing life practices make it challenging to engage in the REKO shopping practice in the long run (Lam, 2020).

As such, REKO needs to continually evolve and engage with consumers to remain relevant and resilient. The initiators of ROA position themselves in favour of increasing trust by cultivating a direct relationship between producer and consumer. Commonly, consumers of AFNs are invited to get directly involved in how the food is produced, i.e., to ask the producer, visit the production unit, and communicate with the producer when something is not right (Delibas, 2021). This is valid also for ROA.

Another set of challenges lies in the endeavour of identifying suitable smallholders for some of the food categories. The interviewee referred to difficulties in finding a meat products provider who fits the profile of the network. This also affects the plans of expansion and the wish to augment the product range, named by the interviewee.

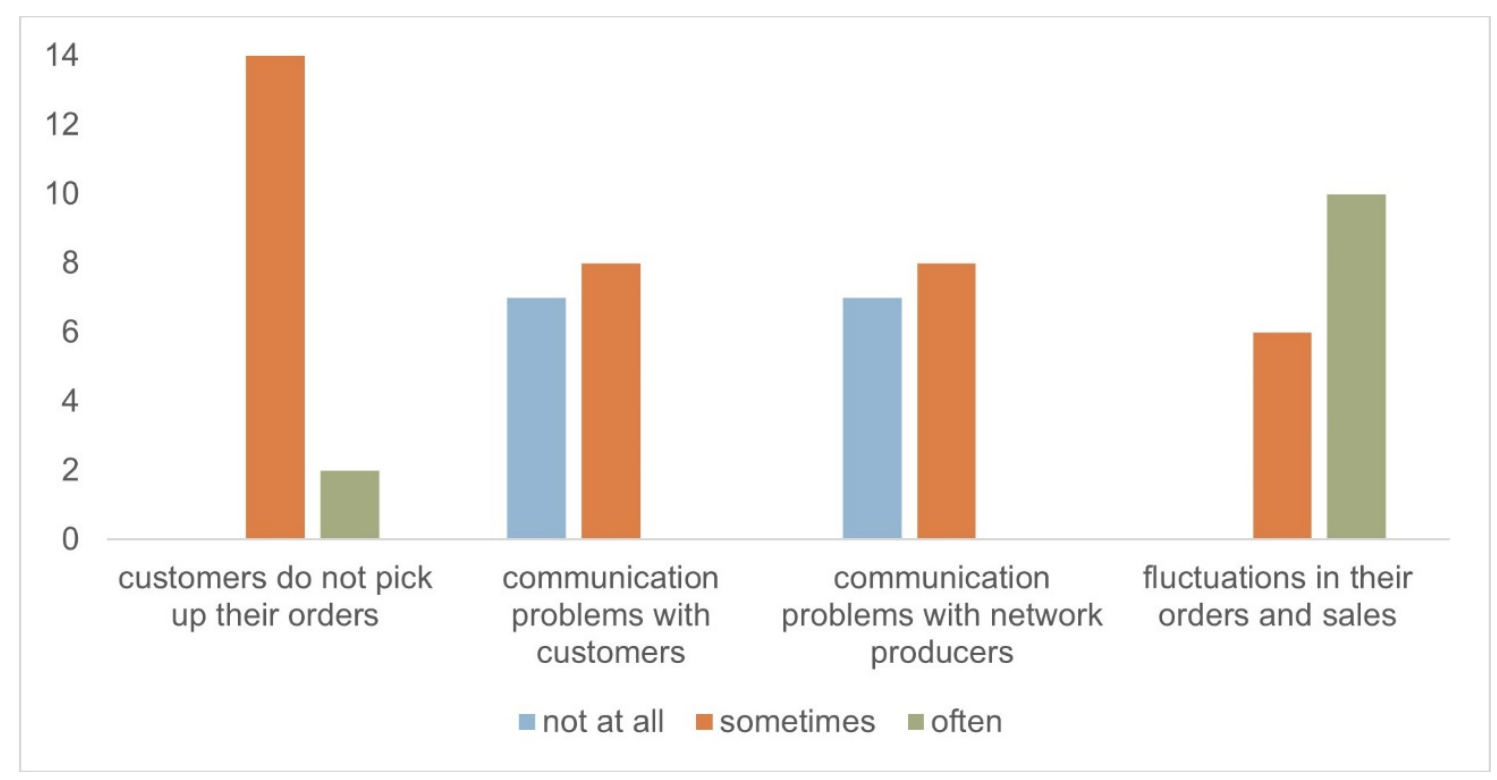

Figure 8: Challenges and disadvantages of being a ROA producer 
Other challenges specified in the survey are rather minor, as for example in some cases the consumers do not pick up their orders, or very seldom occur communication problems with the consumers or with the fellow producers (Figure 8). As some producers have seasonal products, they have limited capacities, similar to those who deliver fresh wild mushrooms. For this kind of products, the weather conditions also play a major role.

\title{
ROA advertisement and transparency
}

As we can see, the extensive usage and application of technology has not only induced changes and adjustments in marketing and distribution systems, but it has generated a new type of consumer, who operates in an omni-channel context, using both digital and physical media, and upholds long-range connections with numerous firms and other stakeholders (Martínez-Ruiz et al., 2021).

A certain volume of coverage through traditional media vehicles such as newspapers, which helped to drive awareness of the ROA REKO opportunity, was noted also by Lam (2020) for the Finish case, but personal social networks, both on- and offline, were relevant for encouraging other to join the network (Lam, 2020). Postings from food bloggers are also considered as trustworthy source of information about the initiative, and the same is the situation with specific influencers. Own online media presence as well as special actions and events on public holidays facilitated and gained publicity for ROA. The FB site "ROA know and rate us", as well as their Instagram account is also a great promotion platform and an additional interaction site for producers and consumers. Further on, the consumers also rate and praise ROA on their own personal FB and Instagram. These mostly supportive contents and feedback are also a great help and encouragement for the producers:

\begin{abstract}
"The ROA model of direct marketing helps us to meet those who order online at established meeting points. The diversity of products in this group makes these meetings a complete experience for the customer and this helps us, supports all the manufacturers. This is how our sales increased and we ended up with the customer relationship being more than a producer-buyer interaction, a friendship. As the orders are online, we get to keep in touch with the customers and, thus, we receive pictures of various pasta dishes. Their creativity inspires us, makes us happyand makes us surpass ourselves" (ROA producer in Lică, 2021; our translation).
\end{abstract}

In these communities, administrators, and producers as well as consumers have their share in the co-creation of their virtual space and real realm (Martínez-Ruiz et al., 2021).

Transparency is an important aspect when building trust, so the ROA producers make great efforts to make their production process as visible as possible for the consumers, for them to gain knowledge about the products and the production process. This practice is also in line with the idea of communicating about the producers, the products, the production methods, to be open to discussion and contact stated by the creator of the original REKO model (Szymoniuk \& Valtari, 2018). The products from the smallholders tell a story, their origin and stages of manufacture are visible to consumers (Delibas, 2021). Facebook is an appropriate platform for communicating and creating a trust relationship, which is mainly based on transparency. Telling the story behind the product helps also to justify the price set for the product, it is a way to distinguish the producer and the product (Szymoniuk \& Valtari, 2018).

The AFNs emphasise rather on the "soft quality" aspects (Barbera \& Dagnesa, 2016), highlighting the characteristics of the involved stakeholders and the local framework, focussing on trust 
relations, respect for the environment, community values, and producers' liability, on food properties such as taste, aesthetic, socio-cultural environment of its origin, and the social dimension of embeddedness, societal benefits of goods, and on gastronomic virtues (HavadiNagy, 2021). The surveyed network not only promise safe, nutritious and healthy products, but the soft quality features are complemented by "hard quality" aspects (Barbera \& Dagnesa, 2016), meaning registered and authorised production units.

\section{CONCLUSIONS}

In this survey we analysed the REKO type short food supply chain based in Cluj-Napoca, Romania, as an example of sustainable marketing strategy. We addressed aspects such as how the network operates, the profile of the participating producers and the marketed products, the costs and benefits for the members, as well as challenges faced by the alternative marketing channel. A possible future survey of the ROA consumers could complete the insight in the network gained through the present analysis of secondary sources, the interview with one cofounder and the survey among the producers.

According to the current assessment, ROA follows the guiding principles of a REKO network, meaning that it markets its own ethically or organically produced local foods in a transparent way. According to the results of the survey among the producers, we notice mainly young, innovative entrepreneurs with mostly recently established businesses. This type of marketing channel could be suitable for producers and farmers in the proximity of larger urban areas, where the earlier mentioned preconditions (internet access, social network skills, transparency, brand loyalty) are met and where the networks can gain consumers who have the resources for and interest in quality food. However, even though this type of consumers is growing in number, the AFNs are competing against each other for a limited number of clients, and REKO consumption is rather a niche activity within routinised everyday life food consumption.

Concluding the benefits of being a ROA member, we can stress out the horizontal integration and a support network among the producers, the feeling of belonging to a community. Apart from the social advantages, the economic aspect, meaning the access to a further marketing channel, is also worth mentioning.

The main challenges of the network manifest in attaining and particularly maintaining a pool of active consumers, which would make the ROA membership of the food producers also economically viable. Aside from that, the lack of a supportive legal and political framework is common for grassroot initiatives of direct marketing in Romania. Although Romania officially adopted the "Farm to Fork" EU policies, measures and guidelines which would facilitate the formal development of these endeavours are missing or incomplete. Despite the increasing demand for qualitative regional products, this current situation, namely the lack of real support of public policies for smallholders (Havadi-Nagy, 2021), the weakly developed idea of selfgovernment, and not firmly established in practice, confine the short food supply chains to a niche phenomenon in comparison with the conventional food marketing and distribution. 


\section{REFERENCES}

BARBERA, F. \& DAGNESA, J. (2016). Building Alternatives from the Bottom-up: The Case of Alternative Food Networks. Agriculture and Agricultural Science Procedia, 8, 324-331.

BUNILĂ, I. (2021). Cum funcționează cea mai mare rețea din România pentru comandarea alimentelor direct de la producători [How Does the Largest Network in Romania for Ordering Food Directly from Producers Work?]. Retrieved 23 May 2021, from https://adevarul.ro/locale/buzau/cum-functioneaza-cea-mai-mare-retearomania-comandarea-alimentelor-direct-producatori-1_60487c265163ec4271bf9f1e/index.html

COŞMAN, O. (2021). ROMO, grupul care aduce la un loc producătorii români şi consumatorii [ROMO, the Group That Brings Together Romanian Producers and Consumers]. Retrieved 23 May 2021, from https://startup.ro/romo-de-la-producator-direct-la-consumator-facebook-cosmina-dinu-serban-dinu/

DELIBAS, H. (2021). Trust and the Clean Food Imaginaries: An Analysis of a Short Food Supply Chain from Romania. Future of Food: Journal on Food, Agriculture and Society, 9(2), 1-13.

EHRNSTRÖM-FUENTES, M. \& LEIPÄMAA-LESKINEN, H. (2019). Boundary Negotiations in a Self-Organised GrassrootsLed Food Network: The Case of REKO in Finland. Sustainability, 11(15), 4137.

EHRNSTRÖM-FUENTES, M., JAUHO, M., \& JALLINOJA, P. (2019). Perceptions and Experiences of Sustainability Among Producers in the REKO Alternative Food Network in Finland. Sosiologia, 56(4), 401-419.

ENGESETH, N.M. (2020). Cream of the Crop? A Study of Consumers in the Alternative Food Network REKO in Oslo and Sustainable Transitions in the Norwegian Food System. Master's Thesis, Centre for Development and the Environment, Universitetet i Oslo.

EUROPEAN UNION (2020). Farm to Fork Strategy. For a Fair, Healthy and Environmentally-Friendly Food System. Retrieved 23 May 2021, from https://ec.europa.eu/food/system/files/2020-05/f2f_actionplan_2020_strategy-info_en.pdf

FACEBOOK (2021a). ROA Cluj- vânzare directă [ROA Cluj- direct sale]. Retrieved 23 May 2021, from https://www.facebook.com/groups/1416150211916542/discussion/preview

FACEBOOK (2021b). ROMO Cluj: De la Producător direct la Consumator [ROMO Cluj: From Producer Directly to Consumer]. Retrieved 23 May 2021, from https://m.facebook.com/groups/romo.cluj/permalink/1394183150951013

HAVADI-NAGY, K.X. (2021). Alternative Food Networks in Romania - Effective Instrument for Rural Development? Journal of Settlements and Spatial Planning. Territorial Identities and Sustainable Development. Challenges and Solution. Special Issue, 8, 15-27.

INTERREG EUROPE. Good Practice. REKO Rings - Local Food Groups. Retrieved 12 March 2021, from https://www.interregeurope.eu/policylearning/good-practices/item/1355/reko-rings-local-food-groups/

KUMAR, S., MURPHY, M., TALWAR, S., KAUR, P., \& DHIR, A. (2021). What Drives Brand Love and Purchase Intentions Toward the Local Food Distribution System? A Study of Social Media-based REKO (Fair Consumption) Groups. Journal of Retailing and Consumer Services, 60, 102444.

LAM, A. (2020). Looking Beyond Individual Behaviour: A Social Practice Theory Approach to Understanding Consumer Drop Out in REKO. Master's Thesis, Faculty of Biosciences, Norwegian University of Life Science.

LEGAT DE CLUJ LDC (20.01.2021). ROA Roade Online Ardeleneşti [ROA Transylvanian Products Online]. [Video] Retrieved 2 February 2021, from https://www.youtube.com/watch?v=zsVuDLi7pZU\&t=209s

LEIPÄMAA-LESKINEN, H. (2021). Practicing Mundane Consumer Resistance in the REKO Local Food System. Qualitative Market Research: An International Journal, 24(3), 341-357.

LICĂ, Ş. (2021). REKO, metoda inedită prin care producătorii dintr-o asociaţie şi-au crescut vânzările [REKO, The Unique Method by Which the Producers from an Association Increased Their Sales]. Retrieved 15 May 2021, from https://m.adevarul.ro/locale/cluj-napoca/metoda-inedita-producatorii-dintr-o-asociatie-si-au-crescutvanzarile-1_6093d24c5163ec4271c1df0e/index.html?fbclid=IwAR0HrHVOKIG9X-J4aoF6B5LfZnanqQ8fMgUirlo6MA6vzGBJPHqj4ggHql 
MARTÍNEZ-RUIZ, M.P., GÓMEZ-SUÁREZ, M., JIMÉNEZ-ZARCO, A.I., \& IZQUIERDO-YUSTA, A. (2021). Toward Consumer 4.0 Insights and Opportunities Under the Marketing 4.0 Scenario. Frontiers in Psychology, 11, 3816.

MURPHY, M. (2020). Understanding Local Food Consumption in REKO Groups: An Application of Behavioral Reasoning Theory. Master's Thesis, School of Business and Management, Lappeenranta-Lahti University of Technology LUT.

NISTOR, L. (2015). Discourses About the Meaning of the Local Food. Investigations in Romanian Urban Contexts. In: Megyesi, B. (ed.), The Social Meaning of Food. Socio.hu. Társadalomtudományi Szemle, 3 Special issue in English, 128-144.

RENTING, H., MARSDEN, T., \& BANKS, J. (2003). Understanding Alternative Food Networks: Exploring the Role of Short Food Supply Chains in Rural Development. Environment and Planning A, 35(3), 393-411.

SADIKU, M.N.O., ASHAOLU, T.J., \& MUSA, S.M. (2019). Food Marketing: A Primer. International Journal of Trend in Scientific Research and Development, 3(4), 131-133.

SANTINI, F. \& GOMEZ Y PALOMA, S. (eds.) (2013). Short Food Supply Chains and Local Food Systems in the EU. A State of Play of their Socio-Economic Characteristics. JRC Scientific and Policy Reports, European Commission Joint Research Centre Institute for Prospective Technological Studies. EUR 25911. Luxembourg (Luxembourg). Publications Office of the European Union. JRC80420.

SZYMONIUK, B. \& VALTARI, H. (2018). The REKO System in Finland: A New Model of a Sustainable Marketing Channel. Problemy Ekorozwoju, 13(2), 103-112. Retrieved 10 March 2021, from https://www.researchgate.net/publication/325626982_The_REKO_system_in_Finland_A_new_model_of_a _sustainable_marketing_channel

ZIARUL CLUJEAN (2021). Roa Cluj, grup de producători locali. Vânzare directă, fără intermediari [Roa Cluj, Group of Local Producers. Direct Sale, Without Intermediaries]. Retrieved 6 June 2021, from https://ziarulclujean.ro/foto-roa-cluj-grup-de-producatori-locali-vanzare-directa-faraintermediari/?fbclid=IwAR0-KK8j-yhVs9P3FiuelI6ZgZJxyCBaqq2fmJtNjocSH5JhRivq7FZIXo4 